\title{
Hydrological analysis of the water flow through the Excellence Development Zone (Magdalena, Colombia)
}

\author{
N. Molinares, J. Manga, A. Sisa \& J. Arrieta \\ Water Technologies Research Group. Universidad del Norte, Colombia
}

\begin{abstract}
The Excellence Development Zone is located on the eastern shore of the Magdalena River, and belonged to the Natural Reserve of the Salamanca Park in the Santa Marta's Big Marsh Ramsar site. This zone was split in order to allow the socioeconomic development in Palermo (Sitionuevo, Magdalena). Due to the lack of certain knowledge of the flow behaviour in this zone, and to make an appropriate distribution of the land for different kind of activities, a hydrological study of the EDZ was carried out. According to the data collected, it was determined that the water enters the zone mainly through the Clarin Nuevo drain, across the south portion of the EDZ near to Palermo, meeting the water coming from the sea and the Santa Marta's Big marsh, and going back underground parallel to the Clarin Viejo drain to the Cantagallo marsh. Following that trends and after making a global environmental analysis, it was recommended to improve the structure of the Clarin Nuevo drain in order to settle most of the particulate material in the water from the Magdalena, avoiding public health and environmental problems.
\end{abstract}

Keywords: Excellence Development Zone, sustainable development, water resource management.

\section{Introduction}

Sustainable development has turned into a key topic for socioeconomic growth in all countries around the world. With an appropriate harnessing of natural resources, especially in developing countries which have a significant environmental offer, equilibrium between economic activities, society expansion, and ecosystem protection can be reached. 
One of the most important issues to be carefully analyzed when the sustainability of certain development strategy is discussed is how extent the availability or the maintenance of the natural resources would be committed with the new activities and land uses. The water resources can be quickly damaged by a wide spectrum of economical activities if it is not well know the flow direction through the zone. It may happen, e.g. that groundwater gets contaminated causing, therefore, public health problems and the long-term deterioration of ecosystems.

In this research, a hydrological analysis in the Excellence Development Zone was made, to determine the convenience of permit industrial and commercial activities into it. This analysis was taken as a criterion in a Global Environmental Analysis carried out by the research group and local environmental authorities.

\section{Results and discussions}

\subsection{The Excellence Development Zone (EDZ)}

The Excellence Development Zone (EDZ) is a portion of land located on the east shire of the Magdalena River, from the Clarin Viejo drain to the mouth of the river. The zone belonged to the Natural Reserve of Salamanca Park in the Santa Marta's Big Marsh Ramsar site. This zone was split from the reserve in order to allow the socioeconomic development of citizens in Palermo (Sitionuevo, Magdalena), and also impel industrial and commercial activities on this shore of the river.

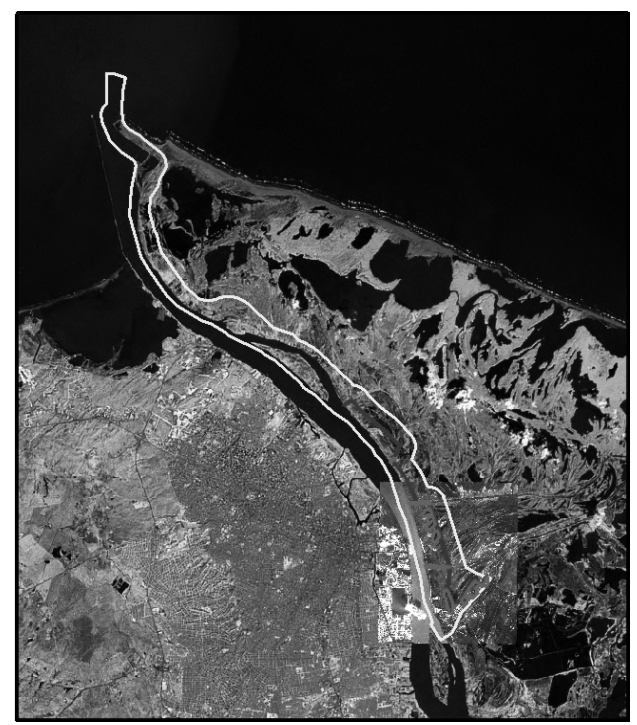

Figure 1: $\quad$ Location of the EDZ.

The EDZ has an approximate length of $22 \mathrm{~km}$ and includes the split zone with $100 \mathrm{~m}$ into the river and $500 \mathrm{~m}$ into the park. According to the available 
cartography, the EDZ has a width of $1350 \mathrm{~m}$ in its southern side, near to Palermo. This widths decrease to $900 \mathrm{~m}$ between the Clarin Viejo and Torno drains, then increase again up to $1200 \mathrm{~m}$ until the Limon drain, and after it, maintains its width in $600 \mathrm{~m}$. See Figure 1.

There are not enough previous studies about this zone. The most relevant one was made by the Colombian Environment, Housing, and Land Development Ministry (MAVDT) which contains the criteria and rules for sustainability evaluation and land ordering in the Ramsar site. However, it is still a lack of basic information.

From another point of view, antropic influence could affect the natural reserve and the Ramsar site transporting pollutants depending on the real direction of the water flow through this zone. Moreover, the environmental problems of the Magdalena River, related to organic matter, nutrients, pathogens and sediments could cause health disturbances and disease on people living there.

Based upon there was no a certain knowledge of the flow behaviour, and to make an appropriate distribution of the land for different kind of activities, it was carried out the hydrological study of the EDZ.

\subsection{Hydrological study}

The Santa Marta's Big Marsh lagoon complex is conformed by more than 20 lagoons with different settling and salinity characteristics, connected by drains and channels, fed mainly by the Magdalena River, the Santa Marta's Sierra Nevada, and the Caribbean Sea. In this complex, the whole system of drains and channels has variable flow-rate magnitudes and directions (Rivera and Caicedo [1]).

As a part of this complex, the hydrological study for the EDZ has to take into account the behaviour of its four (4) main water providers: the Caribbean Sea, The Magdalena River, groundwater flows, and superficial flows. The topographical profile and vegetation distribution were also considered.

\subsubsection{Topography}

Topographical information plays an important role in the determination of the superficial flows direction because the land slope fixes the flow gradient. The estimation of flow gradients, therefore, was based upon topographical information due there was no previous measurements of flow-rates in drains and channels of the EDZ. The profile is shown in Figure 2.

According to the data, land has a slight slope from the Ramsar site to the river, but on the shore a small terrace was found. It was also noted that the elevation tend to get lower from south to north.

This information implies that gradients try to impel superficial flows towards to the river mouth, passing through a big portion of the EDZ. 


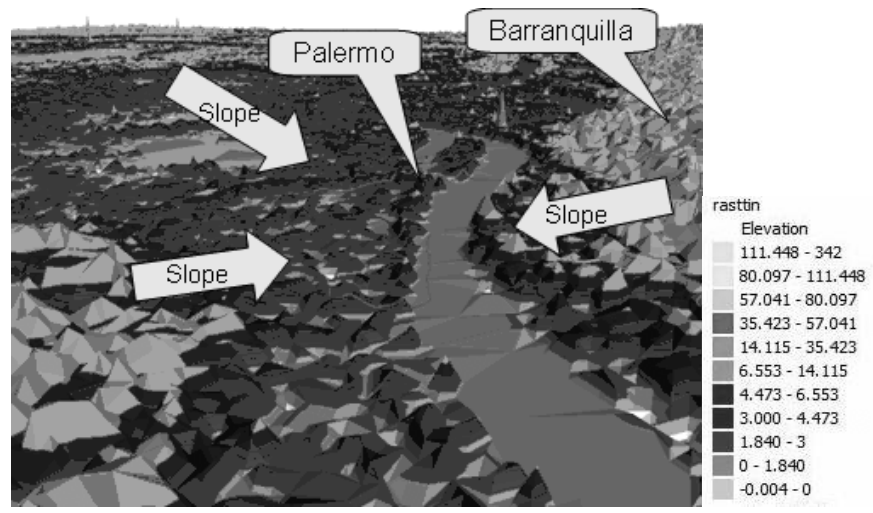

Figure 2: $\quad$ Digital Elevation Model for the EDZ (vertical scale factor $=30$ ).

\subsubsection{Caribbean Sea}

The Caribbean Sea has tide waves with a mean amplitude of $0.35 \mathrm{~m}$ and maximum amplitude of $0.60 \mathrm{~m}$, decreasing to the east side due to the presence of the Sierra Nevada.

The main connection between the Caribbean Sea and the lagoon complex is made through the coastal bar gap in a continuous way, and by soil infiltrations of seawater at the coast.

The combined action of northeast winds and tidal forces modifies the levels of water bodies, and, thus, the water exchange capability in the channels connecting them.

\subsubsection{Magdalena River}

The Magdalena River is the most important water source for the Natural Reserve of Salamanca Park, through the river shore and the Clarin Nuevo drain. In order to analyze its behaviour, the levels of the river at Calamar station $(90 \mathrm{~km}$ up from Palermo) were taken. The observed behaviour is seasonal, reaching the highest levels between June and December, and the lowest between February and April. The mean variability of the $50 \%$ leave curve shows that levels range 2.8 and $7.3 \mathrm{~m}$. along the year.

With levels, the flow-rates at Calamar were estimated. The best fit was obtained with the exponential regression, eqn (1),

$$
Q_{C}=1586.5 \cdot e^{0.2865 \cdot L}
$$

where $\mathrm{Q}_{\mathrm{C}}=$ river flow-rate at Calamar $\left(\mathrm{m}^{3} \cdot \mathrm{s}^{-1}\right)$, and $\mathrm{L}=$ river leave level $(\mathrm{m})$. According eqn (1), the mean annual river flow-rate at Calamar is $7742 \mathrm{~m}^{3} \cdot \mathrm{s}^{-1}$. However, this flow-rate cannot be used directly in the analysis because the station is located before the Dike Channel derivation.

Deeb Sossa S en C [2] established a simple relationship to obtain the flowrates downstream the Dike Channel, eqn. 2,

$$
Q=105+0.9105 \cdot Q_{C}
$$


where $\mathrm{Q}=$ river flow-rate downstream the Calamar station $\left(\mathrm{m}^{3} \cdot \mathrm{s}^{-1}\right)$. By applying the eqn (2), the mean annual river flow-rate at EDZ is $7154 \mathrm{~m}^{3} \cdot \mathrm{s}^{-1}$.

Another relevant issue to be reviewed is Magdalena River water quality. The data analyzed from sampling showed that the principal source of contamination in the EDZ is domestic wastewaters and the transport of some particulate material and NPK fertilizer residues. The highest values identified corresponded to nutrients ( $\mathrm{N}$ and $\mathrm{P}$ ), and coliforms. Nutrients can cause eutrophication, and coliforms generate disease on human settlings. Whichever the case, the water quality of river could threaten the public health and the natural reserve if the inflow coming from gets increased.

\subsubsection{Groundwater flows.}

Based upon the soil characteristics, and taking into account that most of the water exchange in the lagoon complex is made by means of infiltration; groundwater flows could have an important effect on the hydrodynamic stability due possible alterations on phreatic levels which also would change the soil salinity.

In order to estimate the current groundwater conditions, 50 holes were made in EDZ, and in 14 of these phreatic level was measured. Figure 3. The aim of the perforations was to generate a gradient plan that indicates the flow direction near the Cantagallo Marsh.

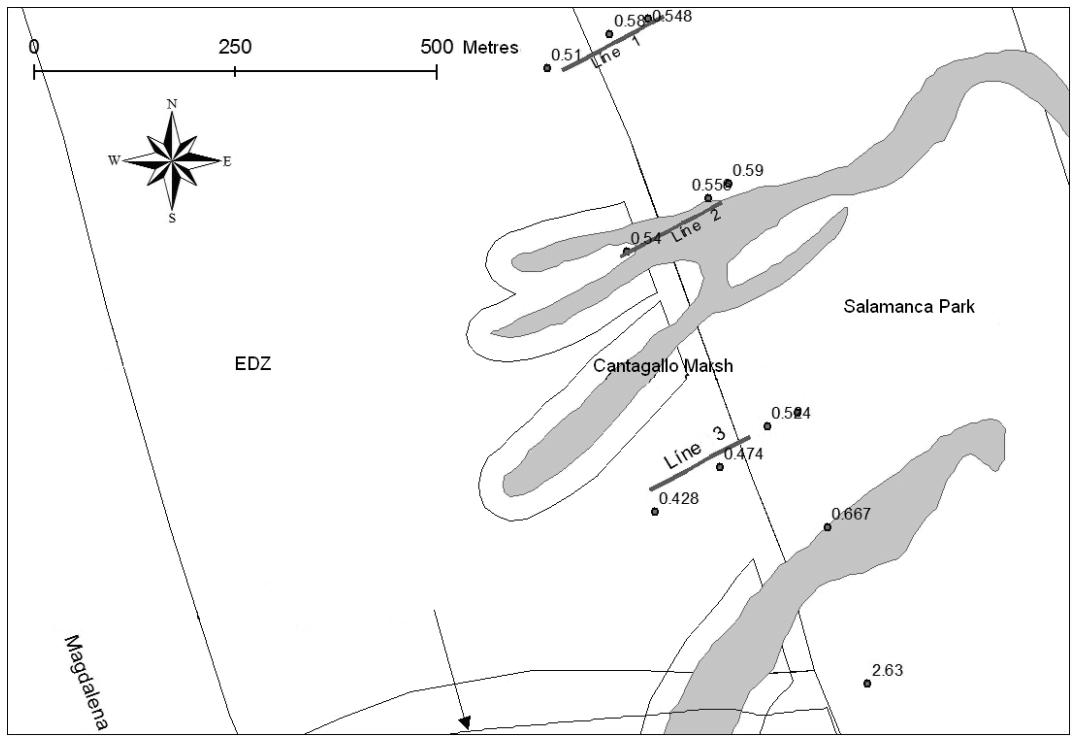

Figure 3: $\quad$ Phreatic level measurement stations for the EDZ.

From the data collected, phreatic surface was calculated, and three sections located at lines 1, 2, and 3 (Figure 3 ) are shown in Figure 4. 

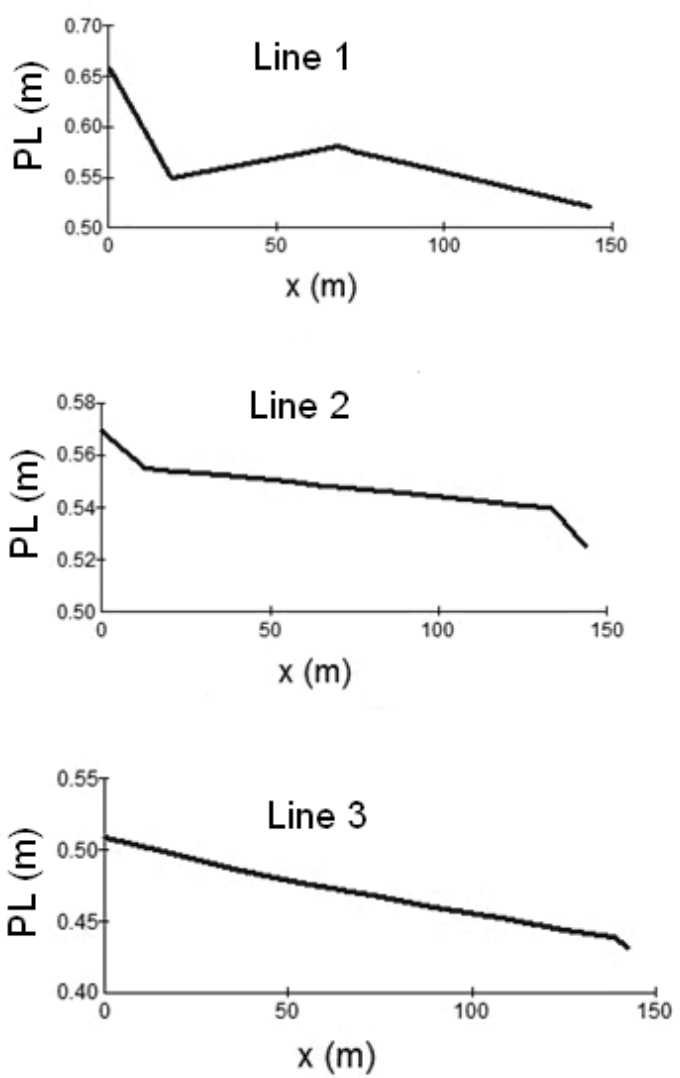

Figure 4: $\quad$ Measured phreatic level (PL) near the Cantagallo Marsh at three different locations. Abscises are measured along the line from east to west.

It can be noted in Figure 4 that the phreatic level descends as the distance from the river is decreased. This fact confirms the assumptions made on the basis of the topographical data.

\subsubsection{Superficial flows}

Concerning superficial flows, there was identified two different trends were recognized. At the north of the EDZ, the water enters from the Magdalena River through El Torno and Limon drains; whereas the south portion of EDZ has a little more complex flow structure.

At the south of the Clarin Viejo drain, the water enters to the Salamanca Park from the Magdalena River passing through the Clarin Nuevo drain. Then water goes from the reserve to the EDZ by infiltration and some little superficial drains and creeks. No flow from the river was identified due to the terrace on the shore. 
This flow configuration limits a close zone between the Clarin Nuevo and Clarin Viejo drains. Nevertheless, erosion processes could create a new entrance to this portion of the EDZ if the shore is not reinforced. The flow direction is shown in Figure 5.

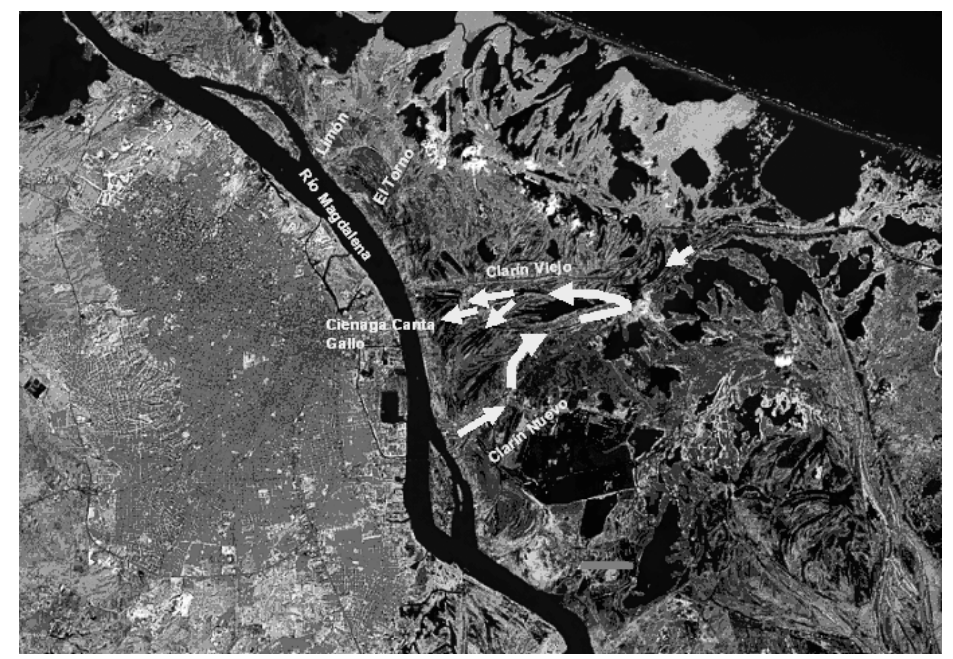

Figure 5: $\quad$ Flow trend through the southern EDZ portion.

\section{Conclusions}

According to the hydrological analysis made for the EDZ, the development of economical activities in the EDZ does not represent a risk for the Natural Reserve of Salamanca Park. The water was found to flow mainly from the reserve to the river slightly deviated to north. Water enters to the reserve through the Clarin Nuevo drain at the south, and through the Torno and Limon drains at the north.

It is recommended to improve the structure of the Clarin Nuevo drain in order to settle most of the particulate material in the water from the Magdalena River, avoiding, therefore, health and environmental problems.

\section{References}

[1] Rivera, M. and Caicedo, D. Informative Chart of Ramsar Wetlands Estuarine Magdalena River's Delta/Santa Marta's Big Marsh System. Colombian Environment Ministry. Colombia, 1998.

[2] Deeb Sossa S en C. Recovery Plan for the Santa Marta's Big Marsh Lagoon Complex, Hydraulic design. Final Inform. DNP, CORPAMAG. Colombia, 1993. 